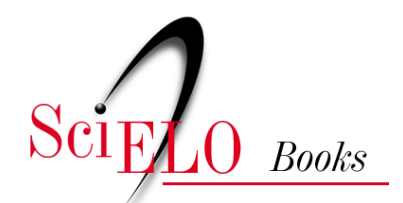

\title{
3. Resolução por programação linear
}

\author{
Aline Guarnieri Gubitoso \\ Vinicius Cifú Lopes
}

\section{SciELO Books / SciELO Livros / SciELO Libros}

GUBITOSO, G., and LOPES, V. C. Resolução por programação linear. In: Alocações, estabilidade e otimização: uma introdução passo a passo [online]. São Bernardo do Campo, SP: Editora UFABC, 2017, pp. 47-79. ISBN: 978-85-6857-682-3. https://doi.org/10.7476/9788568576823.0004.

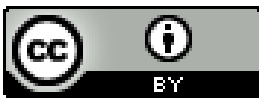

All the contents of this work, except where otherwise noted, is licensed under a Creative Commons Attribution 4.0 International license.

Todo o conteúdo deste trabalho, exceto quando houver ressalva, é publicado sob a licença Creative Commons Atribição 4.0.

Todo el contenido de esta obra, excepto donde se indique lo contrario, está bajo licencia de la licencia $\underline{\text { Creative }}$ Commons Reconocimento 4.0. 


\section{Resolução por programação linear}

A primeira investigação geral do problema do casamento foi a teoria de Gale; Shapley (1962), isto é, o algoritmo de deferred acceptance, seguida de seu desenvolvimento pelos trabalhos dos próprios David Gale e Lloyd Shapley e, também, Alvin Roth, Marilda Sotomayor e outros pesquisadores.

Entretanto, a própria execução uma a uma das rodadas de propostas, descrita no capítulo anterior, não foi a única solução encontrada. Sendo assim, outro método de resolução, interessante para nossa discussão, é a formulação desse problema na forma de otimização linear.

Nossa apresentação será baseada no trabalho de John Vande Vate - como exposto em Gusfield; Irving (1989), mas, para tanto, faremos uma introdução breve à programação linear, sobre a qual o leitor encontrará maiores detalhes em Lins; Calôba (2006) e Brown; Sherbert (1984).

\subsection{Programação linear}

O exercício 37 de Brown; Sherbert (1984, p. 118) requer fazer e vender bolos, tortas e dúzias de biscoito de acordo com a seguinte proporção de ingredientes: 


\begin{tabular}{|c|c|c|c|}
\hline ingrediente $\quad$ produto & bolo & torta & $\begin{array}{l}\text { dúzia de } \\
\text { biscoitos }\end{array}$ \\
\hline maçãs & 3 & 10 & 1 \\
\hline xícaras de açúcar & 1 & 2 & 3 \\
\hline xícaras de farinha & 2 & 3 & 1 \\
\hline
\end{tabular}

Para isso, temos à disposição 840 maçãs, 630 xícaras de açúcar e 450 xícaras de farinha.

Por outro lado, os bolos são vendidos por $\mathrm{R} \$ 8$, as tortas por $\mathrm{R} \$ 6$ e os pacotes de uma dúzia de biscoitos por $\mathrm{R} \$ 5$. De modo a melhor utilizar os ingredientes, desejamos maximizar o valor das vendas, o que significa que desejamos maximizar a função objetivo $V=8 x+6 y+5 z$, sendo:

$$
\begin{gathered}
x=\text { número de bolos; } \\
y=\text { número de tortas; } \\
z=\text { número de dúzias de biscoitos. }
\end{gathered}
$$

Observação: O valor total das vendas é a soma das quantidades vendidas multiplicadas pelos respectivos valores unitários. (Note que, se tivéssemos os custos unitários dos ingredientes, poderíamos calcular o custo total e subtraí-lo do valor das vendas, para tentar maximizar apenas o lucro líquido.)

Essa função $V$ está definida em um domínio, isto é, uma região do espaço tridimensional $O x y z$ delimitada pelas seguintes inequações, devido ao fato de que, para produzirmos tais alimentos, estamos sujeitos às quantidades disponíveis dos ingredientes:

$$
\begin{gathered}
3 x+10 y+1 z \leq 840 \\
1 x+2 y+3 z \leq 630 \\
2 x+3 y+1 z \leq 450
\end{gathered}
$$

e, por uma questão de lógica,

$$
x, y, z \geq 0 \text {. }
$$


A partir dessas equações, montamos uma matriz chamada "tableau", que explicamos a seguir:

\begin{tabular}{c|ccc|ccc|c}
1 & -8 & -6 & -5 & 0 & 0 & 0 & 0 \\
\hline 0 & 3 & 10 & 1 & 1 & 0 & 0 & 840 \\
0 & 1 & 2 & 3 & 0 & 1 & 0 & 630 \\
0 & 2 & 3 & 1 & 0 & 0 & 1 & 450
\end{tabular}

A $1^{\mathrm{a}}$ coluna é fixa; as $2^{\mathrm{a}}, 3^{\mathrm{a}}$ e $4^{\mathrm{a}}$ colunas correspondem às proporções de uso dos ingredientes disponíveis em cada produto, respectivamente, bolos, tortas e dúzias de biscoito; as $5^{\mathrm{a}}, 6^{\mathrm{a}}$ e $7^{\mathrm{a}}$ colunas correspondem às possíveis sobras de maçãs, açúcar e farinha, ou seja, são as quantidades adicionais (também consideradas como variáveis) necessárias para transformar as desigualdades em equações; a $8^{\mathrm{a}}$ coluna considera o total de ingredientes disponíveis. Dessa forma, na $1^{a}$ linha, os valores se referem à função objetivo, mas com os sinais trocados porque, de fato, $V-8 x-6 y-5 z=0$, enquanto que a $2^{\text {a }}$ linha é uma relação das informações sobre as maçãs; a $3^{\mathrm{a}}$ com as informações sobre o açúcar e a $4^{\mathrm{a}}$ com as informações sobre a farinha.

As variáveis que identificam as sobras dos ingredientes adquirem nomes variados na literatura, como "variáveis de folga" ou slack variables.

Uma vez montado o tableau, utilizamos o algoritmo Simplex para resolução do problema. É preciso notar que tanto o tableau que montamos como a descrição das etapas do Simplex são específicas a esse tipo de problema. Outras questões de otimização linear são resolvidas de modo diferente.

$1^{\circ}$ passo: Procurar pela entrada "mais negativa" na primeira linha e selecioná-la; chamamos sua coluna de "coluna pivô". Notamos que o número - 8 é a entrada mais negativa, por isso sua coluna será a "coluna pivô": 


\begin{tabular}{c|c|cc|ccc|c}
\cline { 2 - 6 } 1 & -8 & -6 & -5 & 0 & 0 & 0 & 0 \\
\hline 0 & 3 & 10 & 1 & 1 & 0 & 0 & 840 \\
0 & 1 & 2 & 3 & 0 & 1 & 0 & 630 \\
0 & 2 & 3 & 1 & 0 & 0 & 1 & 450
\end{tabular}

$2^{\circ}$ passo: Em separado, dividir as entradas da última coluna pelas entradas positivas da "coluna pivô" e procurar o menor quociente. Assim:

$$
\begin{aligned}
& 840 \div 3=280 \\
& 630 \div 1=630 \\
& 450 \div 2=225
\end{aligned}
$$

A linha do menor quociente obtido é, então, identificada como "linha pivô", sendo que a célula de interseção desta linha com a "coluna pivô" será chamada de pivô. Notamos que o quociente 225 é o menor, de forma que, sendo ele o quociente de 450 por 2 , a última linha será a "linha pivô", assim como o número 2 é o pivô ao estar na célula em que a "coluna pivô" é interceptada pela "linha pivô":

\begin{tabular}{c|c|c|c|c|c|c|c|}
\cline { 2 - 7 } 1 & -8 & -6 & -5 & 0 & 0 & 0 & 0 \\
\hline 0 & 3 & 10 & 1 & 1 & 0 & 0 & 840 \\
0 & 1 & 2 & 3 & 0 & 1 & 0 & 630 \\
\hline 0 & 2 & 3 & 1 & 0 & 0 & 1 & 450 \\
\hline
\end{tabular}

$3^{\circ}$ passo: Em seguida, dividimos a linha pelo valor do pivô e usamos as operações de escalonamento para zerar o restante da coluna. Isto é, na $1^{a}$ linha, somamos a ela a multiplicação da nova $4^{a}$ linha por 8;

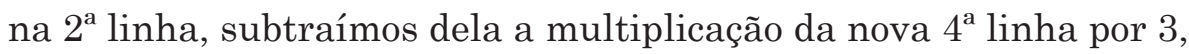
enquanto que, na $3^{\mathrm{a}}$ linha, somente subtraímos dela a nova $4^{\mathrm{a}}$ linha:

\begin{tabular}{c|ccc|ccc|c}
1 & 0 & 6 & -1 & 0 & 0 & 4 & 1800 \\
\hline 0 & 0 & 5,5 & $-0,5$ & 1 & 0 & $-1,5$ & 165 \\
0 & 0 & 0,5 & 2,5 & 0 & 1 & $-0,5$ & 405 \\
0 & 1 & 1,5 & 0,5 & 0 & 0 & 0,5 & 225
\end{tabular}


Esses passos são repetidos até que não haja mais entradas negativas na primeira linha. No caso deste exemplo, ainda há uma entrada negativa - 1, localizada na $4^{\text {a }}$ coluna (nova "coluna pivô"). Então procuramos a nova "linha pivô", dividindo os valores da última coluna pelos positivos da nova "coluna pivô":

$$
\begin{aligned}
& 405 \div 2,5=162 \\
& 225 \div 0,5=450
\end{aligned}
$$

Como o menor quociente é 162, notamos que o novo pivô é 2,5.

\begin{tabular}{c|ccc|ccc|c}
1 & 0 & 6 & -1 & 0 & 0 & 4 & 1800 \\
\hline 0 & 0 & 5,5 & $-0,5$ & 1 & 0 & $-1,5$ & 165 \\
0 & 0 & 0,5 & 2,5 & 0 & 1 & $-0,5$ & 405 \\
0 & 1 & 1,5 & 0,5 & 0 & 0 & 0,5 & 225
\end{tabular}

Dessa forma, o próximo passo é dividir a nova "linha pivô" pelo valor do pivô 2,5 e, utilizando escalonamento, zerar os demais valores dessa coluna. Assim, na $1^{a}$ linha, somamos a nova $3^{\text {a }}$ linha; na $2^{\mathrm{a}}$ linha, somamos o quociente da nova $3^{\mathrm{a}}$ linha por 2 , enquanto que, na $4^{\mathrm{a}}$ linha, subtraímos o quociente da nova $3^{\mathrm{a}}$ linha por 2 . Temos, então:

\begin{tabular}{c|ccc|ccc|c}
1 & 0 & 6,2 & 0 & 0 & 0,4 & 3,8 & 1962 \\
\hline 0 & 0 & 5,6 & 0 & 1 & 0,2 & $-1,6$ & 246 \\
0 & 0 & 0,2 & 1 & 0 & 0,4 & $-0,2$ & 162 \\
0 & 1 & 1,4 & 0 & 0 & $-0,2$ & 0,6 & 144
\end{tabular}

Com base neste último tableau, como não temos mais entradas negativas na primeira linha, chegamos à tabela final. Sua interpretação é a seguinte: sua última coluna contém o valor máximo de $V$ e os valores das variáveis $x, y, z$, identificadas a partir das colunas que formam a matriz identidade, sendo que as demais variáveis são nulas. 
Neste exemplo, descobrimos que, ao maximizar as vendas, ganhamos $\mathrm{R} \$ 1962$ (brutos). Para isso, fazemos e vendemos 144 bolos: percebemos que na $2^{\mathrm{a}}$ coluna, dos bolos, ocorre somente uma única vez o número 1; a interseção de sua linha com a última coluna determina a quantidade de bolos feitos. Também fazemos e vendemos 162 dúzias de biscoito: percebemos que, na $4^{\mathrm{a}}$ coluna dos biscoitos, ocorre somente uma única vez o número 1; a interseção de sua linha com a última coluna determina a quantidade de dúzias de biscoito feitas.

Entretanto, não fazemos nenhuma torta, dado que sua coluna ( $3^{\mathrm{a}}$ coluna) não é composta por zeros e um único 1 . Contudo, a $5^{\mathrm{a}}$ coluna, das sobras de maçãs, tem esse formato. Consequentemente, a interseção da linha restante ( $2^{\mathrm{a}}$ linha) com a última coluna determina o saldo de 246 maçãs, isto é, que sobraram.

\section{Como funciona e quando não funciona}

O algoritmo Simplex é só quinze anos mais velho que o de Gale-Shapley e tem sido estudado profusamente. Faremos somente um resumo de considerações sobre seu funcionamento, mas, para entender melhor o mecanismo, veja textos especializados como Lins; Calôba (2006, caps. 4 e 5). (Cumpre notar que textos diferentes se servem de formulações diversas em que o processo é análogo, mas não idêntico. Por exemplo, Lins e Calôba preferem a linha da função objetivo como última no tableau. Autores que buscam minimizar a função objetivo podem formulá-la inversamente e usar entradas positivas para determinar a "coluna pivô".)

Note, no exemplo, que cada tableau (seja o inicial ou após uma rodada completa dos três passos) também pode ser interpretado como fizemos com o último; obtemos, respectivamente:

- 0 bolos, 0 tortas e 0 dúzias de biscoitos, restando 840 maçãs, 630 xícaras de açúcar e 450 xícaras de farinha.

- 225 bolos, 0 tortas e 0 dúzias de biscoitos, restando 165 maçãs, 405 xícaras de açúcar e 0 xícaras de farinha. (Confira que esses bolos são feitos precisamente com os ingredientes subtraídos das quantidades originais.) 
- 144 bolos, 0 tortas e 162 dúzias de biscoitos, restando 246 maçãs, 0 xícaras de açúcar e 0 xícaras de farinha. (Desistimos de fazer tantos bolos, consumindo menos maçãs e mais açúcar para fazer biscoito.)

Por outro lado, ao delimitarmos a região do espaço tridimensional Oxyz pelas inequações lineares do problema, obtemos um poliedro convexo (sólido com faces e arestas planas e sem concavidade) do qual os pontos $(0,0,0),(225,0,0)$ e $(144,0,162)$ são alguns dos vértices.

Para entendermos a relevância dos vértices, note, primeiramente, que $V=8 x+6 y+5 z$ está definida em todo o espaço $O x y z$; no cálculo básico universitário, mostra-se que $V$ cresce mais rapidamente na direção e sentido do vetor $(8,6,5)$, chamado $\nabla V$ ("gradiente de $V$ '). Podemos imaginar, então, uma pequena bolinha presa dentro do poliedro delimitado pelas restrições do problema linear, mas sobre a qual atua uma força identificada com esse vetor. Assim como se sujeita à força gravitacional, a bolinha tenderia a ir para o ponto mais baixo de um recipiente; naquela situação, ela também tende a deslocar-se para os "últimos" pontos do poliedro, em que o valor de $V$ seja o mais alto. E, assim como no caso do recipiente, cujo fundo pode ser chato ou em forma de uma cunha, esses pontos podem constituir toda uma face ou uma aresta do poliedro, mas, forçosamente, incluem um vértice.

O Simplex foi elaborado, portanto, para procurar o ponto de otimização entre os vértices. Em cada tableau, o algoritmo apresentou-nos um desses vértices e, em sequência, foi ao próximo vértice enquanto o valor da função objetivo $V$ progressivamente aumentou. De fato, na primeira linha, ao eliminarmos as entradas negativas, a última entrada em geral aumenta e nunca diminui (às vezes, pode não aumentar, caso em que o pivô sendo trabalhado é chamado degenerado). Como essa linha corresponde à equação formada pela definição de $V$, sua última entrada é o valor correspondente de $V$ nesse momento.

(A escolha da entrada "mais negativa" na primeira linha busca aumentar o valor de $V$ o mais rápido possível em uma pivotagem, 
embora isso não aconteça necessariamente e outras técnicas possam ser usadas.)

Nesse ínterim, a escolha do menor quociente positivo mantém a última coluna não negativa, subtraindo de cada entrada original um valor menor (nas linhas com quociente positivo) ou somando propriamente (nas linhas com quociente negativo, como a da função objetivo). Isso preserva a factibilidade das variáveis em estudo. Se remontarmos o sistema a partir do tableau, veremos que quaisquer outros valores não negativos para as variáveis acabarão por subtrair algo de $V$, de modo que o valor obtido realmente é máximo.

Porém, duas possibilidades podem atrapalhar a execução do Simplex: não encontrarmos um pivô, ou encontrarmos o mesmo tableau duas vezes.

O primeiro caso é quando uma coluna pivô não tem entradas positivas. Nesse caso, é possível mostrar que a variável correspondente a essa coluna fica livre, ou seja, pode ter um valor positivo arbitrário; então, o poliedro definido pelas inequações é um sólido ilimitado e, portanto, a função $V$ também é ilimitada.

No segundo caso, o valor de $V$ não aumentou entre as duas repetições do mesmo tableau (afinal, esse valor é parte do tableau) e os pivôs envolvidos são todos degenerados. Há casos em que não há outra escolha de pivôs e o método falha.

\subsection{Programação linear pelo Excel}

O procedimento de otimização linear nem sempre é factível manualmente, dado que, em geral, seus problemas já envolvem uma quantidade muito grande de equações dentro do sistema, como é o caso dos problemas de alocação aqui descritos. Por exemplo, um pequeno problema de casamento com somente 6 pessoas (3 casais) já envolverá 15 inequações. Dessa forma, é interessante utilizar ferramentas que agilizem a resolução do sistema linear.

Portanto, incluímos, aqui, um exemplo de resolução de sistemas lineares por meio de planilhas eletrônicas. A título de exemplo, 
trabalharemos o problema anterior de programação linear, em que tivemos que produzir bolos, tortas e biscoitos de modo a maximizar sua receita bruta.

O primeiro passo é montar a tabela com todos os dados e cálculos necessários na planilha. Para facilitar, criamos um "cabeçalho" nas $1^{\mathrm{a}}$ e $2^{\mathrm{a}}$ linhas, em que deixamos a $1^{\mathrm{a}}$ célula vazia (as células que não serão preenchidas mostraremos em cinza nas figuras) e, na $2^{a}$ célula, inserimos "coeficiente de $x$ " ou "coef. $x$ " (que determina a quantidade do produto "bolo" a ser produzida, como determinamos na Seção 3.1), seguido de "coeficiente de $y$ " ou "coef. $y$ " (que determina a quantidade do produto "torta" a ser produzida) na célula seguinte e, depois, de "coeficiente de $z$ " ou "coef. $z$ " (que determina a quantidade de "dúzias de biscoito" a ser produzida). Mantemos as próximas duas células vazias, para, então, na seguinte ( $7^{\mathrm{a}}$ célula), inserirmos "total utilizado" ou "tot. utilizado" e, na subsequente (8 célula), "total disponível” ou "tot. disponível".

\begin{tabular}{|c|c|c|c|c|c|c|c|c|}
\hline \multicolumn{1}{|c|}{} & A & B & C & D & E & F & G & H \\
\hline 1 & & coef. X & coef. Y & coef. Z & & & $\begin{array}{c}\text { tot. } \\
\text { utilizado }\end{array}$ & $\begin{array}{c}\text { tot. } \\
\text { disponivel }\end{array}$ \\
\hline 2 & & &
\end{tabular}

Uma vez feito o "cabeçalho", inserimos a função objetivo $V=8 x+6 y+5 z$ na $3^{\text {a }}$ linha da tabela, ou seja, em sua $1^{a}$ célula inserimos "objetivo" para identificarmos a qual função estamos fazendo referência. Em seguida, incluímos os valores que constituem

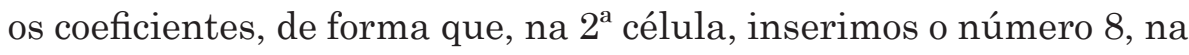

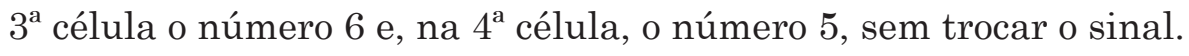

\begin{tabular}{|c|c|c|c|c|c|c|c|c|}
\hline E & A & B & C & D & E & $F$ & G & H \\
\hline$\frac{1}{2}$ & & coef. X & coef. $Y$ & coef. Z & & & $\begin{array}{c}\text { tot. } \\
\text { utilizado }\end{array}$ & $\begin{array}{c}\text { tot. } \\
\text { disponivel }\end{array}$ \\
\hline 3 & objetivo & 8 & $\overline{6}$ & 5 & & & & \\
\hline
\end{tabular}

Após a elaboração destas duas primeiras linhas, pulamos uma linha e começamos a preencher o restante da planilha. Assim, na coluna $A$, iniciamos com a inserção do nome do primeiro ingrediente na $5^{\mathrm{a}}$ linha, "Maçãs"; na $6^{\mathrm{a}}$ linha, inserimos o nome do segundo 
ingrediente, "Açúcar", e, na $7^{\mathrm{a}}$ linha, o nome do terceiro ingrediente, "Farinha".

Ao passo que, na coluna $B$, inserimos a quantidade de cada ingrediente para a fabricação de bolo, ou seja, em sua $5^{a}$ linha inserimos a quantidade necessária de 3 maçãs para a produção de um bolo, enquanto que na $6^{\mathrm{a}}$ linha inserimos a quantidade também necessária de 1 xícara de açúcar para se produzir um bolo e na $7^{\mathrm{a}}$ linha inserimos a quantidade necessária de 2 xícaras de farinha à produção de um bolo.

Consequentemente, na coluna $C$ inserimos as respectivas quantidades de maçãs, xícaras de açúcar e xícaras de farinha para a produção de uma torta, assim como na coluna $D$ inserimos as respectivas quantidades de maçãs, xícaras de açúcar e xícaras de farinha para a produção de uma dúzia de biscoito. Dessa forma, temos:

\begin{tabular}{|c|c|c|c|c|c|c|c|c|}
\hline 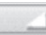 & A & B & C & D & E & $F$ & G & H \\
\hline$\frac{1}{2}$ & & coef. X & coef. $Y$ & coef. Z & & & $\begin{array}{c}\text { tot. } \\
\text { utilizado }\end{array}$ & \begin{tabular}{c|} 
tot. \\
disponivel
\end{tabular} \\
\hline 3 & objetivo & 8 & 6 & 5 & & & & \\
\hline 4 & & & & & & & & \\
\hline 5 & Maçăs & 3 & 10 & 1 & & & & \\
\hline 6 & Açúcar & 1 & 2 & 3 & & & & \\
\hline 7 & Farinha & 2 & 3 & 1 & & & & \\
\hline
\end{tabular}

Em seguida, pulamos as colunas $E, F$ e $G$ e completamos a coluna "tot. disponível" (coluna $H$ ) com os valores determinados pelas inequações da Seção 3.1, ou seja, a partir da $5^{\text {a }}$ linha da coluna $H$ inserimos a quantidade total de 840 maçãs que possuímos, assim como na 6 a linha a quantidade total de 630 xícaras de açúcar e, na $7^{\mathrm{a}}$ linha, a quantidade total de 450 xícaras de farinha à disposição.

\begin{tabular}{|c|c|c|c|c|c|c|c|c|}
\hline 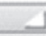 & A & B & C & D & E & $F$ & G & $\mathrm{H}$ \\
\hline$\frac{1}{2}$ & & coef. X & coef. $Y$ & coef. Z & & & $\begin{array}{c}\text { tot. } \\
\text { utilizado }\end{array}$ & $\begin{array}{c}\text { tot. } \\
\text { disponivel }\end{array}$ \\
\hline 3 & objetivo & 8 & 6 & 5 & & $x$ & & \\
\hline \multicolumn{9}{|l|}{4} \\
\hline 5 & Maçãs & 3 & 10 & 1 & & & & 840 \\
\hline 6 & Açúcar & 1 & 2 & 3 & & & & 630 \\
\hline 7 & Farinha & 2 & 3 & 1 & & & & 450 \\
\hline
\end{tabular}


Agora, pulamos a $8^{a}$ linha e, na linha seguinte ( $9^{a}$ linha), inserimos " $x=$ " na coluna $B$, ao passo que inserimos " $y=$ " na coluna $C$ e " $z=$ " na coluna $D$. As células abaixo desses elementos, na $10^{\mathrm{a}}$ linha, são o local onde serão apresentados os valores de cada um desses coeficientes em sua forma mais eficiente, isto é, para se alcançar a maximização da receita bruta. Os valores nestas células irão variar com a execução do Solver, porém, é preciso completar a planilha para iniciar o processo. Para tanto, inserimos o número 1 nestas células.

\begin{tabular}{|c|c|c|c|c|c|c|c|c|}
\hline I & A & B & C & D & E & $\mathbf{F}$ & G & $\mathrm{H}$ \\
\hline$\frac{1}{2}$ & & coef. X & coef. $Y$ & coef. Z & & & $\begin{array}{c}\text { tot. } \\
\text { utilizado }\end{array}$ & $\begin{array}{c}\text { tot. } \\
\text { disponivel }\end{array}$ \\
\hline 3 & objetivo & 8 & 6 & 5 & & & & \\
\hline \multicolumn{9}{|l|}{4} \\
\hline 5 & Maçăs & 3 & 10 & 1 & & & & 840 \\
\hline 6 & Açúcar & 1 & 2 & 3 & & & & 630 \\
\hline 7 & Farinha & 2 & 3 & 1 & & & & 450 \\
\hline \multicolumn{9}{|l|}{8} \\
\hline 9 & & $x=$ & $y=$ & $z=$ & & & & \\
\hline 10 & & & & & & & & \\
\hline
\end{tabular}

Depois, incluímos as fórmulas para o cálculo da otimização na coluna $G$ : na $3^{\text {a }}$ linha dessa coluna inserimos a fórmula $=B 3$ * $B 10+C 3 * C 10+D 3 * D 10$ que realiza a multiplicação dos números contidos nas células $B 3, C 3$ e $D 3$ com os números correspondentes contidos nas células $B 10, C 10$ e $D 10$ e, depois, somados entre si. Depois, na $5^{\text {a }}$ linha, inserimos a fórmula $=B 5 * B 10+C 5 * C 10+D 5$ * $D 10$, que determina a quantidade de maçãs usada na fabricação de bolos, tortas e dúzias de biscoito. Assim, fazemos o mesmo nas linhas seguintes, de forma que na $6^{\text {a }}$, seja inserida a fórmula $=B 6$ * $B 10+C 6 * C 10+D 6 * D 10$ para a quantidade de xícaras de açúcar e, na $7^{\text {a }}$, a fórmula $=B 7 * B 10+C 7 * C 10+D 7 * D 10$ para a quantidade de xícaras de farinha.

O leitor com prática no Excel experimentará selecionar a célula $G 5$, clicar no quadrado que aparece no seu canto inferior direito e "arrastar" para as demais células para completamento automático; contudo, é preciso cuidado e verificar que os índices 
10 serão indevidamente também modificados. Um jeito de resolver isso é através do uso do cifrão $\$$ ao escrever a fórmula em $G 5$ : esse símbolo fixa a identificação da linha ou coluna que o seguir, por exemplo, em $B \$ 10$ ou $\$ B \$ 10$, quando copiamos para todo um grupo de células. Porém, no exemplo de emparelhamento, veremos como realizar todas as somas com uma única operação matricial.

Por conseguinte, as fórmulas determinam o valor 19 na célula G3, 14 na célula $G 5$ e 6 nas células $G 6$ e $G 7$ (enquanto o Solver ainda não foi executado).

\begin{tabular}{|c|c|c|c|c|c|c|c|c|}
\hline 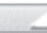 & A & B & C & D & E & $\mathrm{F}$ & G & H \\
\hline $\begin{array}{l}1 \\
2\end{array}$ & & coef. X & coef. Y & coef. Z & & & $\begin{array}{c}\text { tot. } \\
\text { utilizado }\end{array}$ & $\begin{array}{c}\text { tot. } \\
\text { disponivel }\end{array}$ \\
\hline 3 & objetivo & 8 & 6 & 5 & & & 19 & \\
\hline \multicolumn{9}{|l|}{4} \\
\hline 5 & Maçâs & 3 & 10 & 1 & & & 14 & 840 \\
\hline 6 & Açúcar & 1 & 2 & 3 & & & $\overline{6}$ & 630 \\
\hline 7 & Farinha & 2 & 3 & 1 & & & 6 & 450 \\
\hline \multicolumn{9}{|l|}{8} \\
\hline 9 & & $x=$ & $y=$ & $z=$ & & & & \\
\hline 10 & & & & & & & & \\
\hline
\end{tabular}

O passo seguinte é utilizar a ferramenta Solver do programa Excel, que pode ser encontrada na aba "Ferramentas" ou na aba "Dados", juntamente com outras ferramentas de análise.

Se for necessário instalá-lo, vá ao menu principal do Excel, item "Ferramentas" ou "Opções", subitem "Add-ins" ou "Suplementos", procure por "solver" e proceda com as instruções na tela. Essa operação pode não funcionar, informando que o arquivo "solver. xlam" não está presente. Nesse caso, rode a reinstalação do Office para incluir o item "Ferramentas Compartilhadas do Office", subitem "Aplicação Básica Visual" e refaça a operação.

Uma vez disponível e selecionado o Solver, acompanhe o preenchimento de seu "quadro de diálogo" na próxima figura.

O primeiro passo é determinar a "Célula de Destino", isto é, a célula que acumula o valor calculado da função objetivo, que, neste caso, é a célula $G 3$, cuja fórmula soma os produtos dos coeficientes de $x, y$ e $z$ pelos valores dessas variáveis. Para selecioná-la, 
podemos clicar no botão disponível à direita do campo de preenchimento; o quadro de diálogo será substituído por outro, menor, que o usuário pode ignorar e optar por selecionar a célula desejada diretamente na própria planilha; de imediato, o quadro de diálogo será restaurado com o campo preenchido. (Estes cifrões serão inseridos pelo próprio programa para fixar a identificação das células.)

Em seguida, como desejamos maximizar a renda bruta, selecionamos a opção "Máx.". As "Células Variáveis" serão as células $B 10, C 10$ e $D 10$ que identificam os valores dos coeficientes que irão mudar de acordo com a execução do Solver; elas também podem ser selecionadas, como um intervalo de células, com o uso do botão à direita do campo.

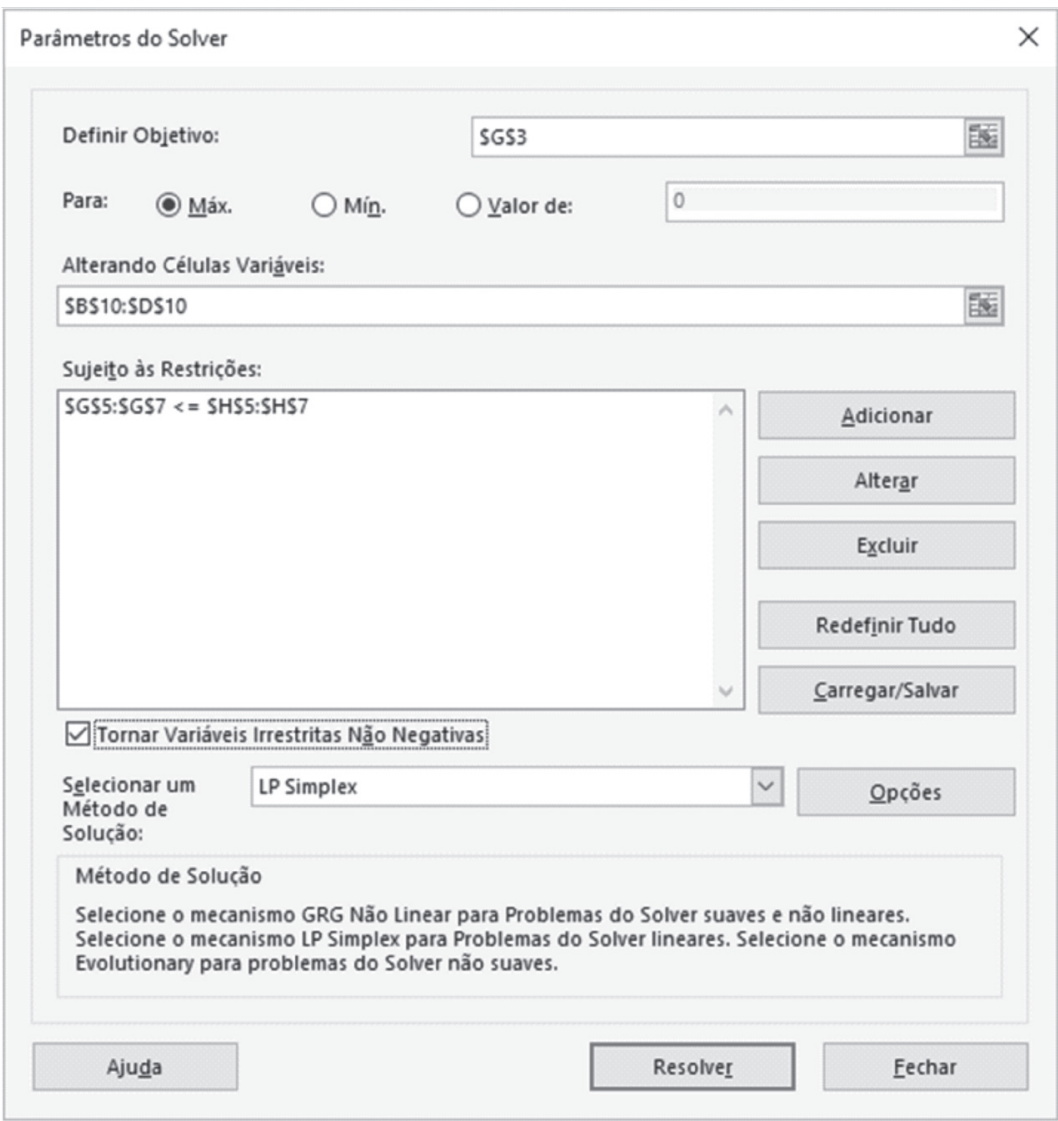


Por fim, inserimos as restrições no quadro de diálogo, de modo que, por uma questão de lógica, os valores de $B 10, C 10$ e $D 10$ devem ser maiores ou iguais a zero e os valores de $G 5, G 6$ e $G 7$ ser menores ou iguais aos valores de $H 5, H 6$ e $H 7$, respectivamente. Podemos tratar as duas situações do mesmo modo, mas, também, selecionar, especificamente, a opção que aparece mais abaixo, "Tornar Variáveis Irrestritas Não Negativas”, para tratar o primeiro conjunto de condições, que é muito comum. Para as outras restrições, clicamos o botão "Adicionar" e selecionamos os intervalos de células no novo quadro de diálogo, assim como a relação de desigualdade entre eles.

Uma vez incluídos os elementos de análise, selecionamos "LP Simplex" como modelo de solução e, então, clicamos em "Resolver". Em vista disso, o Solver começa a ser executado e, se ele encontrar uma solução, automaticamente substituirá os valores na tabela por novos, os quais maximizam a receita bruta. Logo, temos a seguinte tabela reformulada pelo Solver:

\begin{tabular}{|c|c|c|c|c|c|c|c|c|}
\hline & A & B & C & D & E & $\mathrm{F}$ & G & $\mathrm{H}$ \\
\hline $\begin{array}{l}1 \\
2\end{array}$ & & coef. X & coef. Y & coef. Z & & & $\begin{array}{c}\text { tot. } \\
\text { utilizado }\end{array}$ & $\begin{array}{c}\text { tot. } \\
\text { disponivel }\end{array}$ \\
\hline 3 & objetivo & 8 & 6 & 5 & & & 1962 & \\
\hline \multicolumn{9}{|l|}{4} \\
\hline 5 & Maçãs & 3 & 10 & 1 & & & 594 & 840 \\
\hline 6 & Açúcar & 1 & 2 & 3 & & & 630 & 630 \\
\hline 7 & Farinha & 2 & 3 & 1 & & & 450 & 450 \\
\hline \multicolumn{9}{|l|}{8} \\
\hline 9 & & $x=$ & $y=$ & $z=$ & & & & \\
\hline 10 & & 144 & $\underline{0}$ & 162 & & & & \\
\hline
\end{tabular}

Isso significa que o valor da função objetivo é de R\$ 1962 (brutos), devido aos 144 bolos (na célula $B 10$ ) e 162 dúzias de biscoitos (na célula $D 10$ ) produzidos. Entretanto, não fazemos nenhuma torta, dado que a célula $C 10$ está zerada.

Além disso, podemos notar que todas as quantidades de xícaras de açúcar e de xícaras de farinha disponíveis foram utilizadas, ao passo que somente 594 maçãs foram utilizadas, o que resulta num saldo de 246 maçãs.

Portanto, se voltarmos à primeira seção, verificaremos que os resultados obtidos pela programação linear no Excel coincidem 
com a resolução manual do sistema. Dessa forma, utilizaremos essa técnica para a resolução de problemas do casamento.

\subsection{Otimização linear no problema do casamento}

Para que o problema do casamento possa ser resolvido pela programação linear, devemos, primeiramente, expressá-lo em um sistema de equações e inequações lineares. Para isso, os primeiros elementos a serem considerados são o número de pessoas no problema, o que determina a quantidade de equações necessárias, e se ocorre ou não a formação de um casal entre um homem $H$ e uma mulher $M$.

$\rightarrow$ Definição e notação: Para denotar o pareamento entre $H$ e $M$, utilizaremos a variável booleana $X_{H M}$ ou $X(H, M)$, que pode assumir somente dois valores: 0 (falso) quando $H$ e $M$ não estão casados ou 1 (verdadeiro) quando $H-M$. Note que sempre temos $X(H, M) \geq 0$.

Demonstramos o processo de alocação estável de casais a seguir, com um exemplo, utilizando o Excel com o Solver. A título de exemplo, tomamos o universo de 5 homens e 5 mulheres, sendo eles: Victor $(V)$; Wilson $(W)$; Xavier $(X)$; Yuri $(Y)$; Zé $(Z)$; Ana $(A)$; Beatriz $(B)$; Carolina $(C)$; Débora $(D)$; Érica $(E)$.

As pessoas de ambos os grupos continuam a listar as pessoas do grupo oposto segundo uma ordem de preferência; utilizamos, aqui, as mesmas listas de preferências que em nosso primeiro exemplo, na Seção 1.2:

$\begin{array}{llll}\text { Victor: } & A>C>D>E>B & \text { Ana: } & Z>W>V>Y>X \\ \text { Wilson: } & A>D>E>B>C & \text { Beatriz: } & V>X>Y>Z>W \\ \text { Xavier: } & D>C>B>A>E & \text { Carolina: } & Z>W>V>X>Y \\ \text { Yuri: } & A>D>B>E>C & \text { Débora: } & V>W>Y>X>Z \\ \text { Zé: } & C>D>A>B>E & \text { Érica: } & W>Z>X>Y>V\end{array}$


Com o intuito de montar as equações, notaremos que, de acordo com o número $2 n$ de agentes envolvidos no problema (10 pessoas, 5 de cada grupo), são necessárias $2 n+n^{2}$ equações. Ao substituirmos $n$ por 5 descobrimos o número total de 35 equações para este problema.

Destas 35 equações, as 10 primeiras equações dirão respeito a cada um dos indivíduos, em que se determinam todos os possíveis pares que ele pode fazer com as pessoas do grupo oposto. As demais 25 equações dirão respeito às preferências dos parceiros sob cada possível emparelhamento.

Lembre que:

$$
X_{H M}= \begin{cases}1 & \text { se } H-M \\ 0 & \text { se não }\end{cases}
$$

Dessa forma, montamos, primeiramente, as equações de cada indivíduo de um dos grupos, como dos homens, em que cada homem tem uma equação que soma todos os pares que ele forma com cada uma das mulheres do problema. Além disso, essas equações devem ser igualadas a 1, pois temos a certeza de que existe a possibilidade de formação de algum desses pares, isto é, para cada agente algum par pode ser formado e deverá ser único. Assim:

- Para cada homem $H$, temos a equação $\Sigma_{M} X(H, M)=1$.

- Para cada mulher $M$, temos a equação $\Sigma_{H} X(H, M)=1$.

$\rightarrow$ Justificativa: Como cada variável $X_{H M}$ só pode valer 0 ou 1 , a soma de todas as variáveis para cada agente deve igualar 1 , o que garante que, dessas variáveis, somente uma valha 1 (correspondendo ao casamento realizado) e as outras valham 0 (casamentos não realizados).

Por exemplo, a equação de Victor deve conter os potenciais pares dele com Ana $(V A)$, Beatriz $(V B)$, Carolina $(V C)$, Débora $(V D)$, e Érica $(V E)$,com sua soma igualada a 1 :

$$
\text { Victor: } X_{V A}+X_{V B}+X_{V C}+X_{V D}+X_{V E}=1
$$


Depois, fazemos o mesmo procedimento com o outro grupo, das mulheres. Por exemplo, a equação de Ana deve conter seus pares com Victor $(V A)$, Wilson $(W A)$, Xavier $(X A)$, Yuri $(Y A)$, e Zé $(Z A)$ com soma igual a 1 :

$$
\text { Ana: } X_{V A}+X_{W A}+X_{X A}+X_{Y A}+X_{Z A}=1
$$

Assim, ao final, temos as seguintes equações de cada pessoa:

$\begin{array}{lll}\text { Victor: } & X_{V A}+X_{V B}+X_{V C}+X_{V D}+X_{V E} & =1 \\ \text { Wilson: } & X_{W A}+X_{W B}+X_{W C}+X_{W D}+X_{W E} & =1 \\ \text { Xavier: } & X_{X A}+X_{X B}+X_{X C}+X_{X D}+X_{X E} & =1 \\ \text { Yuri: } & X_{Y A}+X_{Y B}+X_{Y C}+X_{Y D}+X_{Y E} & =1 \\ \text { Zé: } & X_{Z A}+X_{Z B}+X_{Z C}+X_{Z D}+X_{Z E} & =1 \\ \text { Ana: } & X_{V A}+X_{W A}+X_{X A}+X_{Y A}+X_{Z A} & =1 \\ \text { Beatriz: } & X_{V B}+X_{W B}+X_{X B}+X_{Y B}+X_{Z B} & =1 \\ \text { Carolina: } & X_{V C}+X_{W C}+X_{X C}+X_{Y C}+X_{Z C} & =1 \\ \text { Débora: } & X_{V D}+X_{W D}+X_{X D}+X_{Y D}+X_{Z D} & =1 \\ \text { Érica: } & X_{V E}+X_{W E}+X_{X E}+X_{Y E}+X_{Z E} & =1\end{array}$

Em seguida, montamos um outro tipo de equações (as 25 restantes), mais propriamente desigualdades, em que contemplamos cada possível par entre homens e mulheres. Para formação desse segundo tipo de equações, primeiro somamos os pares que a mulher da equação acredita serem piores do que o parceiro emparelhado com ela (isto é, os pares com homens que estão depois de seu par em sua lista de preferência). Depois, subtraímos os pares que o homem da equação prefere à sua parceira (ou seja, os pares com as mulheres mais preferíveis que sua parceira em sua lista de preferência). Ou seja, para o par $(H, M)$, temos:

$$
\sum_{H \prime<M^{H}} X\left(H^{\prime}, M\right)-\sum_{M \prime>H_{H} M} X\left(H, M^{\prime}\right) \leq 0
$$


$\rightarrow$ Justificativa: Essa desigualdade é montada de modo, que o par $(H, M)$ não possa ser um par de bloqueio. De fato, se $H$ e $M$ forem casados, ambas as somas são nulas. Caso contrário, como cada soma vale 0 ou 1 , se $M$ estiver pareada a um homem $H^{\prime}$ que considere inferior a $H$ (a soma esquerda é 1), então $H$ deverá estar pareado a uma mulher $M^{\prime}$ que considere superior a $M$ (a soma direita será 1 ); por outro lado, se $H$ estiver pareado a uma mulher que considere inferior a $M$ (a soma direita é 0), então $M$ deverá estar pareada a um homem que considere superior a $H$ (a soma esquerda será 0 ).

Dessa forma, primeiro selecionamos um homem e uma mulher para, então, montar uma equação para este par. Por exemplo, notamos que o par Victor e Ana tem a seguinte equação: Ana considera Yuri e Xavier como menos preferíveis que Victor, enquanto que, na segunda parte, Victor considera que não há ninguém mais preferível que Ana. Ou seja:

$$
V A:\left(X_{Y A}+X_{X A}\right)-(0) \leq 0
$$

Continuamos a montar as equações de cada par. A fim de facilitar, montamos primeiro todos os possíveis pares de Victor, isto é, Victor e Ana; Victor e Beatriz; Victor e Carolina; Victor e Débora; Victor e Érica:

$$
\begin{array}{lll}
V A: & \left(X_{Y A}+X_{X A}\right)-(0) & \leq 0 \\
V B: & \left(X_{X B}+X_{Y B}+X_{Z B}+X_{W B}\right)-\left(X_{V A}+X_{V C}+X_{V D}+X_{V E}\right) & \leq 0 \\
V C: & \left(X_{X C}+X_{Y C}\right)-\left(X_{V A}\right) & \leq 0 \\
V D: & \left(X_{W D}+X_{Y D}+X_{X D}+X_{Z D}\right)-\left(X_{V A}+X_{V C}\right) & \leq 0 \\
V E: & (0)-\left(X_{V A}+X_{V C}+X_{V D}\right) & \leq 0
\end{array}
$$

Em seguida, todos os possíveis pares de que Wilson pode fazer parte, isto é, Wilson e Ana; Wilson e Beatriz; Wilson e Carolina; Wilson e Débora e Wilson e Érica: 
$W A: \quad\left(X_{V A}+X_{Y A}+X_{X A}\right)-(0)$

$W B: \quad(0)-\left(X_{W A}+X_{W D}+X_{W E}\right)$

$W C: \quad\left(X_{V C}+X_{X C}+X_{Y C}\right)-\left(X_{W A}+X_{W D}+X_{W E}+X_{W B}\right)$

$\leq 0$

$W D: \quad\left(X_{Y D}+X_{X D}+X_{Z D}\right)-\left(X_{W A}\right)$

$\leq 0$

$W E: \quad\left(X_{Z E}+X_{X E}+X_{Y E}+X_{V E}\right)-\left(X_{W A}+X_{W D}\right)$

$\leq 0$

Assim como os pares em que Xavier é contemplado, isto é, Xavier e Ana; Xavier e Beatriz; Xavier e Carolina; Xavier e Débora e Xavier e Érica:

$X A$ :

(0) $-\left(X_{X D}+X_{X C}+X_{X B}\right)$ $\leq 0$

$X B: \quad\left(X_{Y B}+X_{Z B}+X_{W B}\right)-\left(X_{X D}+X_{X C}\right)$ $\leq 0$

$X C: \quad\left(X_{Y C}\right)-\left(X_{X D}\right)$ $\leq 0$

$X D: \quad\left(X_{Z D}\right)-(0)$ $\leq 0$

$X E: \quad\left(X_{Y E}+X_{V E}\right)-\left(X_{X D}+X_{X C}+X_{X B}+X_{X A}+X_{X B}\right)$ $\leq 0$

Agora, os pares de Yuri, isto é, Yuri e Ana; Yuri e Beatriz; Yuri e Carolina; Yuri e Débora e Yuri e Érica:

$Y A: \quad\left(X_{X A}\right)-(0)$

$Y B: \quad\left(X_{Z B}+X_{W B}\right)-\left(X_{Y A}+X_{Y D}\right)$

$Y C: \quad(0)-\left(X_{Y A}+X_{Y D}+X_{Y B}+X_{Y E}\right)$

$Y D: \quad\left(X_{X D}+X_{Z D}\right)-\left(X_{Y A}\right)$

$Y E: \quad\left(X_{V E}\right)-\left(X_{Y A}+X_{Y D}+X_{Y B}\right)$ $\leq 0$

$\leq 0$

$\leq 0$

$\leq 0$

$\leq 0$

E, por fim, os pares em que Zé está presente, isto é, Zé e Ana; Zé e Beatriz; Zé e Carolina; Zé e Débora e Zé e Érica:

$Z A: \quad\left(X_{W A}+X_{V A}+X_{Y A}+X_{X A}\right)-\left(X_{Z C}+X_{Z D}\right)$

$Z B: \quad\left(X_{W B}\right)-\left(X_{Z C}+X_{Z D}+X_{Z A}\right)$ $\leq 0$

$Z C: \quad\left(X_{W C}+X_{V C}+X_{X C}+X_{Y C}\right)-(0)$ $\leq 0$

$Z D: \quad(0)-\left(X_{Z C}\right)$ $\leq 0$

$Z E: \quad\left(X_{X E}+X_{Y E}+X_{V E}\right)-\left(X_{Z C}+X_{Z D}+X_{Z A}+X_{Z B}\right)$ $\leq 0$ 
Notamos que todos os possíveis pares que cada mulher pode ter também estão contemplados nas equações, dado que cada mulher é parte de um dos pares que cada homem tem.

Ainda não falamos da função objetivo, que construiremos mais tarde.

Observação: Via de regra, na programação linear geral, o Simplex oferece resultados que são números reais. As equações que montamos tratam as variáveis $X(H, M)$ como variáveis booleanas e garantem seus valores como 0 ou 1 a partir da hipótese de serem inteiros. Esta condição, por sua vez, é garantida por um teorema de Vande Vate: todos os vértices do poliedro delimitado pelas restrições usadas têm coordenadas que são todas números inteiros. (GUSFIELD; IRVING, 1989, s. 3.7.2; ROTH; SOTOMAYOR, 1990, s. 3.2.4.)

\section{Exercícios}

1) Podemos usar o mesmo sistema de equações e inequações para simular as propostas realizadas pelas mulheres?

Resposta: As equações são as mesmas por simetria, enquanto cada inequação

$$
\sum_{H^{\prime}<{ }_{M} H} X\left(H^{\prime}, M\right)-\sum_{M \prime>_{H} M} X\left(H, M^{\prime}\right) \leq 0
$$

equivale à das mulheres propondo

$$
\sum_{M^{\prime}<H^{M}} X\left(H, M^{\prime}\right)-\sum_{H^{\prime}>_{M} H} X\left(H^{\prime}, M\right) \leq 0
$$

(note, para tanto, e usando as equações $\Sigma_{H} X(H, M)=1$ e $\Sigma_{M} X(H, M)=1$, que a diferença dos membros esquerdos é $(1-X(H, M))-(1-X(H, M))=0$, ou seja, são iguais). 
2) Mostre que essas inequações equivalem, ainda, à seguinte:

$$
\sum_{M^{\prime}>H^{M}} X\left(H, M^{\prime}\right)+\sum_{H^{\prime}>{ }_{M} H} X\left(H^{\prime}, M\right)+X(H, M) \geq 1
$$

que é apresentada em Roth; Sotomayor (1990, p. 70).

Resposta: Note que o primeiro e o terceiro termos do membro esquerdo, depois de somados, igualam $1-\sum_{\left(M^{\prime}<H^{M}\right)} X\left(H, M^{\prime}\right)$.

3) Como devem ser as equações e inequações para tratar um caso de listas incompletas e números diferentes de homens e mulheres?

Resposta: Devemos formar agora as inequações $\Sigma_{H} X(H, M) \leq 1$ e $\Sigma_{M} X(H, M) \leq 1$, impor $X(H, M)=0$ para qualquer par em que algum dos dois não aceite o outro (ou, equivalentemente, remover essa variável de todo o sistema) e acrescentar a desigualdade do exercício anterior somente para pares $(H, M)$ mutuamente aceitáveis. (ROTH; SOTOMAYOR, 1990, p. 77, devido a ROTHBLUM)

\section{Montagem da planilha e formulação do objetivo}

Uma vez estabelecidas todas as equações necessárias, o passo seguinte para a resolução do problema é seguir os passos do Simplex no Excel. Para isso, temos que inserir todas essas informações numa planilha. Também montaremos a função objetivo.

Assim, primeiro criamos um cabeçalho: $\mathrm{Na} 1^{\mathrm{a}}$ linha, inserimos "equação \variável" ou "eq. \var." que significa, respectivamente, os rótulos das equações e rótulos das variáveis nas equações. $\mathrm{Na}$ célula seguinte, inserimos o par " $V A$ ", na subsequente " $V B$ ", e assim em diante; quando todos os pares de Victor forem inseridos, começamos a inserir os pares de Wilson, e, então, de Xavier, Yuri e Zé, até inserir " $Z E$ ", na $27^{\text {a }}$ célula (coluna $A A$ ). Em seguida, diminuímos a célula seguinte numa menor largura e, nas nas $29^{\mathrm{a}}$ e $30^{a}$ células (colunas $A C$ e $A D$ ) inserimos "variáveis" e também diminuímos a largura da $31^{\mathrm{a}}$ e $32^{\mathrm{a}}$ células. Depois, na $33^{\mathrm{a}}$ célula (coluna $A G$ ), inserimos "totais" e na $34^{a}$ célula (coluna $A H$ ), inserimos "disponível" ou "dispon.". A figura abaixo mostra isso, estando dividida em duas partes para melhor compreensão: 


\begin{tabular}{|c|c|c|c|c|c|c|c|c|c|c|c|c|c|c|c|c|c|}
\hline 1 & A & C & D & $\mathbf{E}$ & $F$ & G & H & I & J & $\mathrm{K}$ & L & & M & $\mathbf{N}$ & 0 & P & $\mathbf{Q}$ \\
\hline 1 & eq. I var. & VA & VB & VC & VD & VE & WA & WB & we & WD & $w$ & & $X A$ & $\mathrm{XB}$ & $x C$ & $X D$ & XE \\
\hline & $\mathbf{R}$ & S & $\mathbf{T}$ & $U$ & v & w & $x$ & $Y$ & $\mathbf{z}$ & AA & $A B$ & $A C$ & $A D$ & $|A| A F$ & AG & AH & \\
\hline
\end{tabular}

Após a elaboração do cabeçalho, diminuímos a espessura da $2^{\mathrm{a}}$ linha e montamos um outro cabeçalho, agora vertical, na $1^{\mathrm{a}}$ coluna

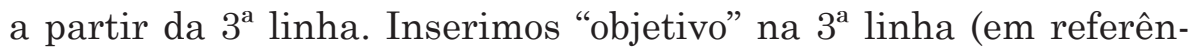
cia à função objetivo de que ainda trataremos). Na linha seguinte, também diminuímos sua espessura, e, então, na $5^{\mathrm{a}}$ linha, iniciamos a inserção das equações: inserimos "Victor" ou " $V$ '. linha seguinte, inserimos "Wilson" ou " $W$ ”; na subsequente, "Xavier" ou " $X$ ”, e assim por diante. Quando todos os homens forem incluídos, inserimos, na linha seguinte, as mulheres, começando por "Ana" ou " $A$ ”, seguida pelas demais mulheres. Por fim, depois que todas forem incluídas, inserimos os pares, começando com " $V A$ ", depois " $V B$ " na seguinte, e assim por diante. Mostramos essa coluna em quatro partes:

\begin{tabular}{|c|c|}
\hline & A \\
\hline 1 & eq. I var. \\
\hline 3 & objetivo \\
\hline 5 & $V$ \\
\hline 6 & $W$ \\
\hline 7 & $X$ \\
\hline 8 & $Y$ \\
\hline 9 & $Z$ \\
\hline
\end{tabular}

\begin{tabular}{|c|c|}
\hline 10 & A \\
\hline 11 & B \\
\hline 12 & C \\
\hline 13 & D \\
\hline 14 & E \\
\hline 15 & VA \\
\hline 16 & VB \\
\hline 17 & VC \\
\hline 18 & VD \\
\hline 19 & VE \\
\hline
\end{tabular}

\begin{tabular}{|l|l|}
\hline 20 & WA \\
\hline 21 & WB \\
\hline 22 & WC \\
\hline 23 & WD \\
\hline 24 & WE \\
\hline 25 & XA \\
\hline 26 & XB \\
\hline 27 & XC \\
\hline 28 & XD \\
\hline 29 & XE \\
\hline
\end{tabular}

\begin{tabular}{|l|l|}
\hline 30 & $Y A$ \\
\hline 31 & $Y B$ \\
\hline 32 & $Y C$ \\
\hline 33 & $Y D$ \\
\hline 34 & $Y E$ \\
\hline 35 & $Z A$ \\
\hline 36 & $Z B$ \\
\hline 37 & $Z C$ \\
\hline 38 & $Z D$ \\
\hline 39 & $Z E$ \\
\hline
\end{tabular}

Uma vez esclarecidos os rótulos (informações dos cabeçalhos horizontal e vertical), inserimos os valores da função objetivo: o primeiro par é $V A$, sendo assim, temos de verificar qual é a posição de $A$ na lista de preferências de $V$; como $A$ é sua $1^{\mathrm{a}}$ opção, inserimos o número 1 na interseção da $3^{\text {a }}$ linha com a coluna $V A$; em seguida,

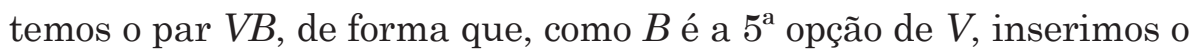
número 5 na célula $D 3$ e continuamos fazendo o mesmo procedimento com cada um dos pares. Explicaremos essa função mais à frente.

Ao final, temos a seguinte função objetivo - quando são os homens que propõem (somente exibimos o começo da linha):

\begin{tabular}{|c|c|c|c|c|c|c|c|c|c|c|c|c|c|c|c|c|}
\hline 1 & A & $\begin{array}{ll}B & C \\
\end{array}$ & D & $E$ & $F$ & G & H & $I$ & J & K & L & M & $\mathbf{N}$ & 0 & $P$ & $Q$ \\
\hline 1 & eq. I var. & VA & VB & vc & VD & VE & WA & WB & wc & WD & WE & $\mathrm{XA}$ & $\mathrm{XB}$ & $\mathrm{XC}$ & XD & $\mathrm{XE}$ \\
\hline 3 & objetivo & 1 & 5 & 2 & 3 & 4 & 1 & 4 & 5 & 2 & 3 & 4 & 3 & 2 & 1 & 5 \\
\hline
\end{tabular}


O passo seguinte é inserir os coeficientes das equações feitas acima. Assim, na $5^{\text {a }}$ linha, como para Victor qualquer pareamento com ele e alguma das mulheres é possível, insere-se o número 1 nas células C5 a G5 (porque estão nas colunas dos pares em que Victor está presente), enquanto que nas demais células até a célula da coluna $A A$ dessa linha inserimos 0 porque Victor não consta em mais nenhum par. Ademais, como a equação de Victor é igualada a 1, inserimos esse número na coluna "dispon." (coluna $A G$ ) na linha desta equação ( $5^{\text {a }}$ linha). Aqui estão as duas partes dessa linha:

\begin{tabular}{|c|c|c|c|c|c|c|c|c|c|c|c|c|c|c|c|c|}
\hline 1 & A & B $\quad$ C & D & E & $F$ & G & $\mathrm{H}$ & I & $J$ & K & L & M & $\mathbf{N}$ & 0 & $\mathbf{P}$ & Q \\
\hline 1 & eq. I var. & VA & VB & $\mathrm{vc}$ & Vo & VE & WA & WB & wc & WD & WE & $X A$ & $\mathrm{XB}$ & $x c$ & XD & $\mathrm{XE}$ \\
\hline 3 & objetivo & 1 & 5 & 2 & 3 & 4 & 1 & 4 & 5 & 2 & 3 & 4 & 3 & 2 & 1 & 5 \\
\hline 5 & v & 1 & 1 & 1 & 1 & 1 & 0 & 0 & 0 & 0 & 0 & 0 & 0 & 0 & 0 & 0 \\
\hline & $\mathbf{R}$ & 5 & $T$ & U & V & W & $x$ & $Y$ & $z$ & AA & AC & AD & AAF & AG & $\mathrm{AH}$ & \\
\hline & $Y A$ & YB & YC & YD & YE & $Z A$ & ZB & $\mathrm{ZC}$ & ZD & $\mathrm{ZE}$ & \multicolumn{2}{|c|}{ variáveis } & & totais & dispon. & \\
\hline & 1 & 3 & 5 & 2 & 4 & 3 & 4 & 1 & 2 & 5 & & & & & & \\
\hline & 0 & 0 & 0 & 0 & 0 & 0 & 0 & 0 & 0 & 0 & & & & & 1 & \\
\hline
\end{tabular}

Consequentemente, na $6^{\mathrm{a}}$ linha, que se refere a Wilson, somente nas células de $H 6$ a $I 6$ inserimos o número 1, de forma que, nas células restantes até a coluna $A A$, inserimos o número 0 , mas, também, depois, inserimos o número 1 na coluna $A G$. O mesmo é feito com as equações de cada um dos homens (na imagem, demonstramos apenas até o par XE):

\begin{tabular}{|c|c|c|c|c|c|c|c|c|c|c|c|c|c|c|c|c|}
\hline 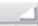 & A & C & D & E & $\mathbf{F}$ & G & H & I & J & K & L & M & $\mathrm{N}$ & 0 & P & $Q$ \\
\hline 1 & eq. I var. & VA & VB & $\mathrm{vc}$ & Vo & VE & WA & WB & wc & WD & WE & $X A$ & $\mathrm{XB}$ & $\mathrm{xC}$ & $\mathrm{XD}$ & $\mathrm{XE}$ \\
\hline 3 & objetivo & 1 & 5 & 2 & 3 & 4 & 1 & 4 & 5 & 2 & 3 & 4 & 3 & 2 & 1 & 5 \\
\hline 5 & v & 1 & 1 & 1 & 1 & 1 & 0 & 0 & 0 & 0 & 0 & 0 & 0 & 0 & 0 & 0 \\
\hline 6 & w & 0 & 0 & 0 & 0 & 0 & 1 & 1 & 1 & 1 & 1 & 0 & 0 & 0 & 0 & 0 \\
\hline 7 & $x$ & 0 & 0 & 0 & 0 & 0 & 0 & 0 & 0 & 0 & 0 & 1 & 1 & 1 & 1 & 1 \\
\hline 8 & $\gamma$ & 0 & 0 & 0 & 0 & 0 & 0 & 0 & 0 & 0 & 0 & 0 & 0 & 0 & 0 & 0 \\
\hline 9 & $z$ & 0 & 0 & 0 & 0 & 0 & 0 & 0 & 0 & 0 & 0 & 0 & 0 & 0 & 0 & 0 \\
\hline
\end{tabular}

Depois, o mesmo é feito com as mulheres. Por exemplo, na $10^{\mathrm{a}}$ linha, que se refere a Ana, inserimos o número 1 somente nas células das colunas em que ela é um dos parceiros, sendo elas $C 10, H 10$, $M 10, R 10$ e $W 10$, além de inserirmos na coluna $A G$. Na $11^{\mathrm{a}}$ linha, que se refere a Beatriz, somente inserimos o número 1 nas células $D 11, I 11, N 11, S 11$ e $X 11$ e na coluna $A G$; depois, fazemos o mesmo com Carolina, Débora e Érica (na imagem, demonstramos apenas até o par $X E)$ : 


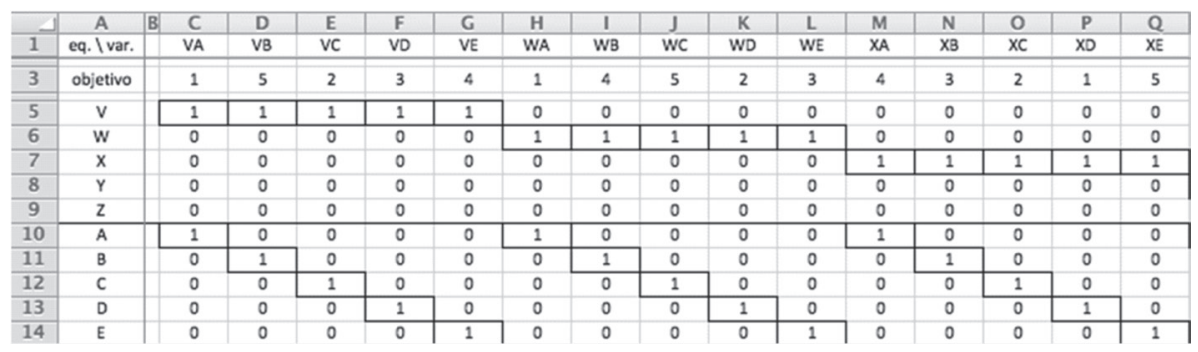

A partir da $15^{\mathrm{a}}$ linha, os coeficientes são 1,0 ou -1 e analisamos as inequações dos casais da seguinte maneira: os pares que estão dentro da primeira somatória recebem o número 1, enquanto que os que estão na segunda somatória, devido ao sinal de subtração, tornam-se -1, e os demais pares, que não aparecem em nenhum dos parênteses, recebem o número 0 , assim como as células da coluna $A G$, uma vez que essas expressões são sempre menores ou iguais a 0 . Por exemplo, $V A$ tem a seguinte equação:

$$
V A:\left(X_{Y A}+X_{X A}\right)-(0) \leq 0
$$

Logo, na linha deste par ( $15^{\mathrm{a}}$ linha) procuramos a célula que faz interseção com a coluna de $Y A$, no caso $R 15$, e inserimos o número 1. Também procuramos a interseção com $X A$, no caso $M 15$, e inserimos o número 1. Como não há mais nenhum par explícito, nas demais células, inserimos o número 0 .

Na linha seguinte, temos o par $V B$, com a seguinte inequação:

$$
V B:\left(X_{X B}+X_{Y B}+X_{Z B}+X_{W B}\right)-\left(X_{V A}+X_{V C}+X_{V D}+X_{V E}\right) \leq 0
$$

Assim, procuramos as interseções com os emparelhamentos do primeiro parêntese, no caso $I 16, N 16, S 16, X 16$, e inserimos o número 1. Depois procuramos as interseções com os pares do segundo parêntese, no caso $C 16, E 16, F 16$ e $G 16$, e inserimos o número - 1, enquanto que, nas demais células da linha, inserimos o número zero.

Fazemos isso com cada inequação referente a um par e obtemos a seguinte tabela (na imagem, demonstramos apenas até a coluna do par $X E)$ : 


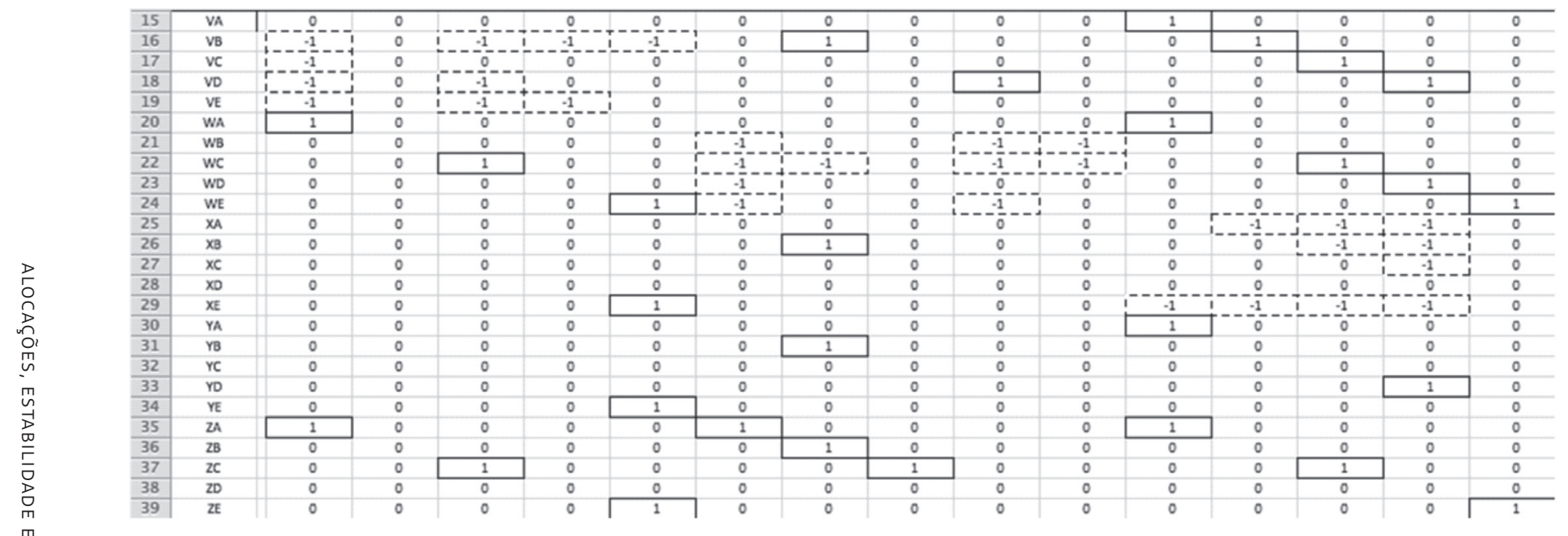


O próximo passo é inserir os pares na coluna "Variáveis", (colunas $A C$ e $A D$ ), como referência ao rótulo das variáveis propriamente ditas, de forma que, na célula $A C 9$, inserimos " $V A$ ”. Na célula abaixo, inserimos " $V B$ " e assim em diante; depois, nas células ao lado (na coluna $A D$ ), inserimos o número 1 , simplesmente para completar a planilha, uma vez que os valores nestas células irão variar com a execução do Solver (aqui mostramos em duas partes):

\begin{tabular}{l|l|l|l|l|}
\hline & $\mathrm{A}$ & $\mathrm{AB}$ & $\mathrm{AC}$ & $\mathrm{AD}$ \\
\hline 1 & & & \multicolumn{2}{|c|}{ variáveis } \\
\hline 2 & & & & \\
\hline 3 & & & & \\
\hline 4 & & & & \\
\hline 5 & & & & \\
\hline 6 & & & & \\
\hline 7 & & & & \\
\hline 8 & & & & \\
\hline 9 & & & VA & 1 \\
\hline 10 & & & VB & 1 \\
\hline 11 & & & VC & 1 \\
\hline 12 & & & VD & 1 \\
\hline 13 & & & VE & 1 \\
\hline 14 & & & WA & 1 \\
\hline 15 & & & WB & 1 \\
\hline 16 & & & WC & 1 \\
\hline
\end{tabular}

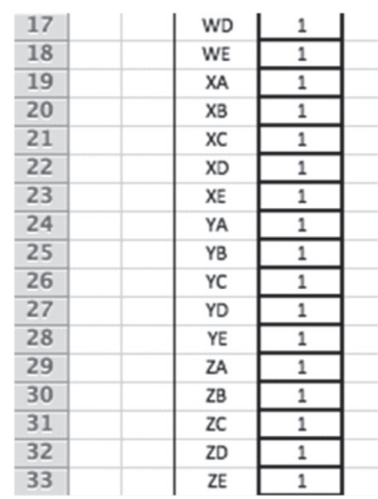

Em seguida, inserimos as fórmulas para o cálculo da otimização na coluna $A G$ : Selecionamos da $5^{\text {a }}$ linha até a $39^{\mathrm{a}}$ linha dessa coluna, pressionamos a tecla "F2", inserimos a fórmula

$$
\text { = MATRIZ.MULT (C5:AA39;AD9: AD33) }
$$

e pressionamos, simultaneamente, "Ctrl", "Shift" e "Enter". A fórmula calcula o produto da matriz das células de $C 5$ até a célula $A A 39$ com o vetor da coluna $A D$ da $9^{\text {a }}$ linha até a $33^{\text {a }}$ linha. Trata-se de uma fórmula cujo resultado deve preencher todo um intervalo de células e o procedimento indica isso para o programa. Após o procedimento, o Excel exibe essa fórmula entre chaves para destacar essa particularidade. Em AG3, pomos:

$$
\text { = MATRIZ.MULT }(C 3: A A 3 ; A D 9: A D 33) \text {, }
$$


que calcula a função objetivo com os parâmetros na coluna $A D$, da $9^{\mathrm{a}}$ à $33^{\mathrm{a}}$ linha. Enquanto não executamos o Solver, essas fórmulas calculam números que só depois serão otimizados. (O leitor deve experimentar o uso das fórmulas matriciais também no exemplo da seção anterior.)

Portanto, o próximo passo é executar o Solver. Para isso, selecionamos a aba "Ferramentas" ou "Dados" do menu principal do Excel e, em seguida, selecionamos Solver. Assim, primeiramente temos de determinar a "Célula de Destino", isto é, a célula que acumula o valor calculado da função objetivo, que, neste caso, é a célula AG3. Para obter uma alocação mais favorável aos homens, selecionamos, então, a opção "Mín.", como explicaremos a seguir. Depois, selecionamos as "Células Variáveis", isto é, os valores dos coeficientes que irão mudar de acordo com a execução do Solver, sendo eles as células da coluna $A D$ da $9^{\text {a }}$ linha até a $33^{\text {a }}$ linha. Por fim, inserimos as restrições no quadro de diálogo, de modo que, como montamos as equações e inequações, os valores de $A G 5$ até $A G 14$ devem ser iguais aos valores de $A H 5$ até $A H 14$ e os valores de $A G 15$ até $A G 39$ devem ser menores ou iguais aos valores de $A H 15$ até $A H 39$, respectivamente, enquanto as variáveis incógnitas devem ser não negativas. 


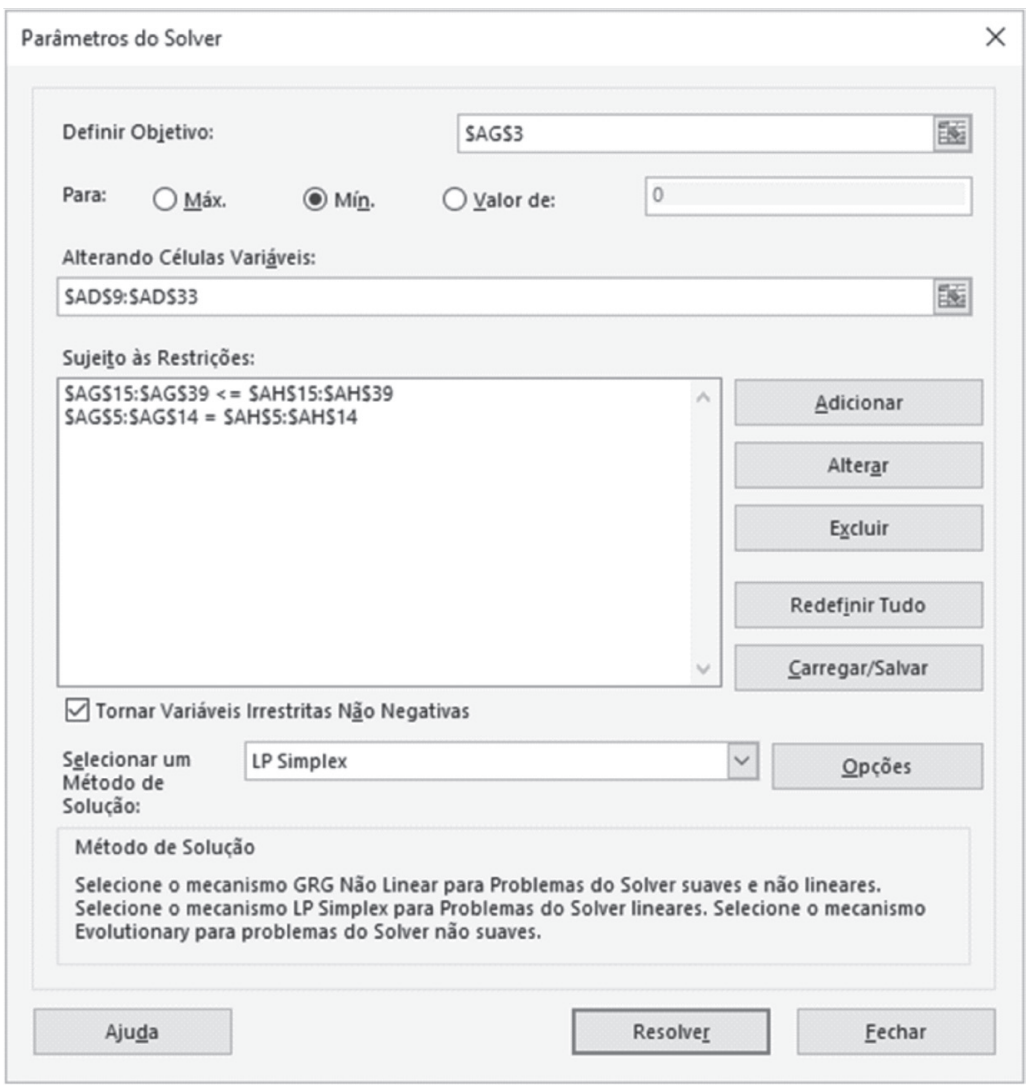

Uma vez incluídos os elementos de análise, selecionamos "LP Simplex" como modelo de solução e, então, clicamos em "Resolver". Em vista disso, o Solver começa a ser executado, com os homens sendo os mais favorecidos. Na solução encontrada, observamos, primeiro, os pares formados nas colunas $A C$ e $A D$, sendo eles os pares que, na coluna $A D$, pela otimização do Solver, obtiveram o número 1. Portanto, temos: Victor e Debora (VD); Wilson e Ana (WA); Xavier e Beatriz $(X B)$; Yuri e Érica $(Y E)$; e Zé e Carolina $(Z C)$. Notamos que esse resultado é exatamente igual ao que obtivemos manualmente na Seção 1.2 .

A próxima figura exibe a planilha completa que montamos. 


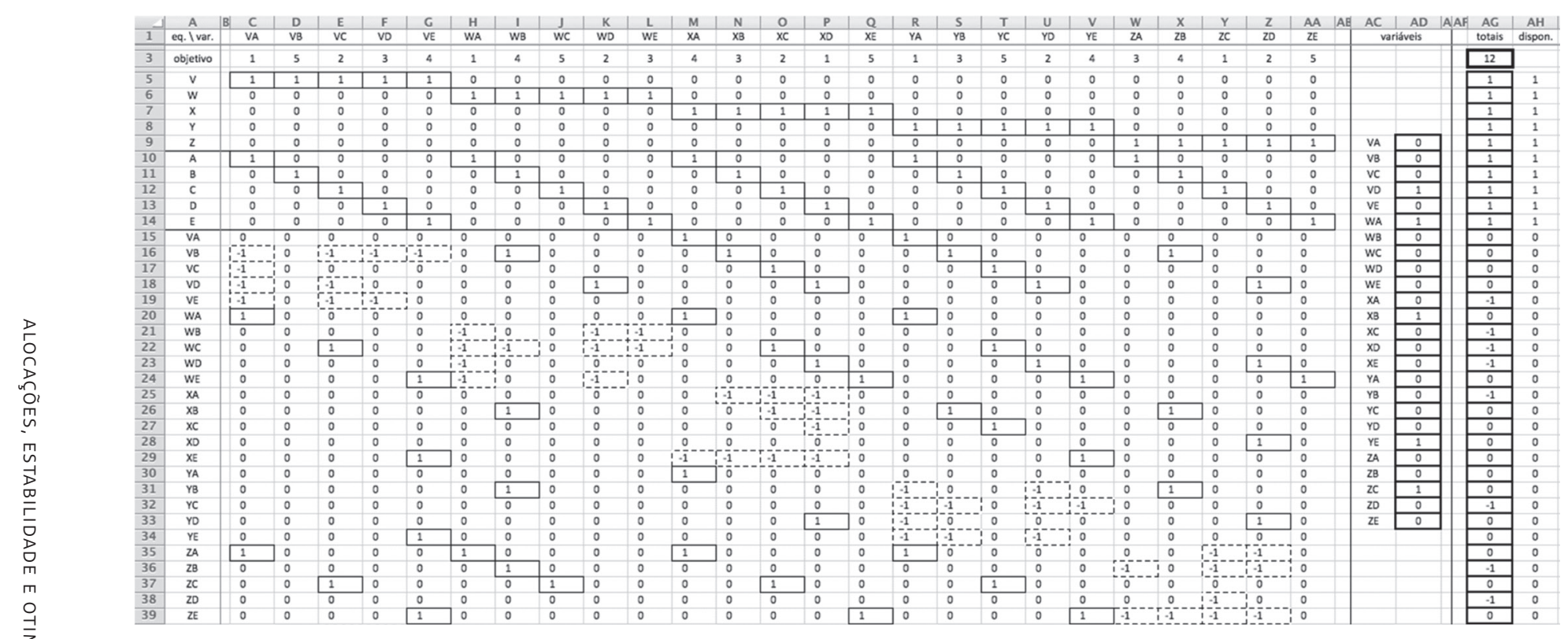




\section{Explicação da função objetivo}

Também devemos observar, nesta tabela final, o valor da função objetivo, que significa a otimização da soma das posições dos pares de todos os homens.

$\rightarrow$ Notação: Para denotar a posição de $M$ na lista de preferência de $H$, utilizamos a expressão $P_{H}(M)$. Ao passo que, para denotar a posição de $H$ na lista de preferência de $M$, utilizamos a expressão $P_{M}(H)$.

A função objetivo que minimizamos é simplesmente:

$$
\sum_{H, M} P_{H}(M) \cdot X(H, M)
$$

-Justificativa: Essa somatória adiciona o termo exibido, simultaneamente, para todos os homens e mulheres. Porém, para cada homem $H$, somente uma variável $X(H, M)$ vale 1 e as demais valem 0 , então, somente um fator $P_{H}(M)$ é efetivamente adicionado e é o que corresponde à esposa de $H$, enquanto os demais termos são anulados.

Dessa forma, o número 12 , na célula $A G$, significa a soma das 3 posições que Victor tem em sua lista de preferências até sua parceira, Débora, com mais 1 posição da lista de Wilson até Ana; além de mais 3 posições na lista de Xavier; 4 posições na lista de Yuri e 1 posição na lista de Zé:

$\left.\begin{array}{lll}\text { Victor: } & A>C>D>E>B & \text { posição 3 } \\ \text { Wilson: } & A>D>E>B>C & \text { posição 1 } \\ \text { Xavier: } & D>C>B>A>E & \text { posição 3 } \\ \text { Yuri: } & A>D>B>E>C & \text { posição 4 } \\ \text { Zé: } & C>D>A>B>E & \text { posição 1 }\end{array}\right\}$ total 12


Desse modo, na prática, instruímos o Solver a procurar pela menor soma das distâncias das mulheres nas listas de seus parceiros. Se desejamos uma alocação mais favorável às mulheres, selecionamos "Máx.", porque esta procura pela maior soma das distâncias das mulheres nas listas de seus parceiros, lembrando que o pior pareamento para os homens significa o melhor pareamento para as mulheres. Logo, não é necessário que modifiquemos a função objetivo, uma vez que selecionar "Máx." já significa inverter os sinais de todas as equações como se invertêssemos os papéis dos dois grupos de agentes.

\subsection{Emparelhamento estável igualitário}

Na formulação acima, explicitamos que, ao utilizarmos a programação linear para resolução do problema do casamento, deveríamos optar ou por minimizar a função objetivo, favorecendo, então, o grupo que faz as propostas, ou maximizar essa função, de forma a favorecer o grupo que recebe as propostas. Entretanto, alguns avanços já foram feitos, de forma que esse mecanismo não se restrinja a tais opções.

Assim, é possível a descoberta de emparelhamentos mais igualitários entre os homens e as mulheres a partir da inclusão de "pesos" de preferência ao invés de somente uma lista ordenada.

Por exemplo, podemos tratar homens e mulheres simetricamente e igualmente a partir de uma função objetivo que os contemple dessa forma:

$$
\sum_{H, M}\left[P_{H}(M)+P_{M}(H)\right] \cdot X(H, M)
$$

Essa expressão, na reunião entre homens e mulheres, considera simultaneamente os pesos das preferências de ambos, de acordo com a posição de seu parceiro em sua lista de preferência. 
Dessa forma, é possível formular uma nova função objetivo, com a qual obteremos um resultado de emparelhamento igualitário quando é minimizada.

A Seção 3.6 de Gusfield; Irving (1989) dá três definições de emparelhamentos mais simétricos entre proponentes e seletores, inclusive a somatória acima, e algoritmos eficientes para encontrá-los, utilizando princípios teóricos subjacentes a Gale-Shapley em vez da programação linear geral.

Uma dessas definições permite maior flexibilidade na formulação de listas de preferência, em que cada agente atribui "pontuações" àqueles que deve comparar, em lugar de simples "posições". Por exemplo, o agente $X$ pode expressar o quanto $A>{ }_{X} B$ atribuindo valores reais $P_{X}(A)$ e $P_{X}(B)$ que devem apenas satisfazer $P_{X}(A)<P_{X}(B)$ (note que, quanto menor a pontuação ou nota, melhor a opção).

É possível, até mesmo, estabelecer um "passeio" partindo do emparelhamento ótimo dos homens e chegando ao das mulheres, para escolhermos qualquer ponto entre eles: para $t \in[0,1]$, defina

$$
V(t)=\sum_{H, M}\left[(1-t) \cdot P_{H}(M)+t \cdot P_{M}(H)\right] \cdot X(H, M)
$$

O parâmetro $t$ pode ser identificado em uma célula adicional da planilha que montamos e usado na fórmula da função objetivo $V(t)$ (que é função das variáveis $X_{H M}$ ). Então, $V(0)$ é a função objetivo que, minimizada, induz o emparelhamento ótimo dos homens; $V$ (1) é aquela ótima para as mulheres; corresponde à primeira somatória acima, exceto por um fator de escala, e tem os mesmos pontos de máximo e de mínimo.

Além de possibilidades como essas, Gusfield; Irving (1989, p. 219) propõem tornar a soma das "pontuações" dos homens $\sum_{H, M} P_{H}(M) \cdot X(H, M)$ a mais próxima possível à soma das "pontuações” das mulheres $\sum_{H, M} P_{M}(H) \cdot X(H, M)$. Em Knuth (1997, p. 51), minimiza-se não a somatória, mas uma função de máximo:

$$
\max _{H, M}\left\{P_{H}(M) \cdot X(H, M), P_{M}(H) \cdot X(H, M)\right\}
$$




\subsection{Discussão}

Apresentamos e exemplificamos a resolução de problemas do casamento a partir da otimização linear e do algoritmo Simplex, com a aplicação da ferramenta Solver no Excel.

Como a programação linear pôde, também, resolver um problema envolvendo maçãs, farinha, bolos e tortas, assim como é cotidianamente utilizada na indústria, observamos que expressar o problema do casamento em um sistema de equações e inequações lineares foi mais um exemplo de redução, agora do problema do casamento aos problemas de otimização linear. Nós o utilizamos, também, para apresentar algumas melhorias, especialmente para a busca por emparelhamentos estáveis igualitários.

Destacamos, porém, que esse mecanismo de resolução não é o mais eficiente, porque o de Gale-Shapley requer menos passos e cálculos. Também Gusfield; Irving (1989, s. 3.7.1) apresentam uma redução mais eficiente à programação linear, mas concedem (p. 147) que o sistema de Vande Vate é mais elegante e não requer uma solução preliminar, nem o conceito de rotações que estudaremos somente no problema dos colegas de quarto. 